\title{
Analysis on the Distribution Characteristics of IMIS Enrollment Plan of TCM Colleges in China
}

\author{
Haifeng YANG, Fang MEI, Chao LEI, Qian LIU, \\ Miao ZHANG, Binqian LIU, Yangbo SU* \\ School of Information Engineering \\ Hubei University of TCM \\ Wuhan, China \\ *Corresponding author
}

\author{
Kang CHEN \\ College of Marine Geosciences \\ Ocean University of China \\ Qingdao, China
}

\begin{abstract}
In order to ameliorate the enrollment strategies of the specialty of Information Management \& Information System (IMIS) in Traditional Chinese Medicine(TCM) colleges, we collected and processed the IMIS enrollment plans in $\mathbf{4 2}$ Colleges from 2013 to 2016, and also the actual enrollment volume of 11 TCM colleges from 2013 to 2015. And then, we made a comparis on between TCM colleges and Medical colleges in terms of enrollment scale, structure and also distribution. According to that, several significant features are revealed on the IMIS enrollment plans of TCM Colleges, including frequently fluctuated enrollment scale, relatively larger enrollment scale, significant differences among regions and districts, improvement on structure and quality. And also some potential problems are brought up, such as gaps between planning enrollment and actual enrollment, disproportion with the requirement of TCM informatization, distribution overlap in high extent with medical colleges. It is imperative for TCM colleges to adopt a series of countermeasures to promote their enrollment quality, such as keeping the ir enrollment scales stable, optimizing the distribution and structure of enrollment plan corresponding with the development of TCM informatization, broadening recruiting channels and making much enrollment publicity in advance and so on. This study has great significance for realizing the specialty of IMIS in TCM colleges developed healthily and sustainably.
\end{abstract}

Keywords-TCM Colleges; IMIS; Enrollment; Comparative Study

\section{INTRODUCTION}

For the last 20 years, more and more universities including medical colleges and TCM colleges in China, contributed to cultivate the professionals of IMIS oriented toward Health and Medicine, as a respond to the increasing requirement for talents in Health Informatics and also TCM Informatics [1][2]. Recently, it became more obvious since various fashionable technologies were widely used to ameliorate health service process, management efficiency, and medical environment, such as Data Mining, Machine Learning, Bigdata store and analysis, etc.. Compared with medical colleges, TCM colleges confronted with more challenges in the development of IMIS, because of their relatively insufficient educational resources, more distinctive talents requirements and lower society credence. In order to realize the sustainable development of IMIS in TCM colleges, constructive development strategies were proposed by several education experts in TCM Informatics [2-4], through analyzing the differences between medical colleges and TCM colleges from aspects of cultivation destination, curriculum system and practice teaching, while candidate quality differences and its influence on ultimate cultivation results were nearly neglected[5]. According to the Humanism Learning Theory, study of the characteristic of candidates can make benefit on optimizing the recruit plan and avoiding the cultivation plan divorced from the real situation of candidates. Therefore, in this article we made insights on the candidate features through analyzing IMIS enrollment plan from 2013 to 2016.

\section{MATERIAL AND METHODS}

\section{A. Determination of Research Objects}

In order to determinate the list of colleges, we retrieved the theses delivered from Jan $1^{\text {st }}, 2000$ to Oct $1^{\text {st }}, 2018$ from the CNKI periodical full-text database, by using the search strategy: TI='Infomration Management Special' AND TI='Health' OR TI=' Infomration Management Special' AND TI='Meicine', and 127 articles were returned. 68 colleges or universities were sieved out by extracting the first author's organization from these articles and removing duplicate. After academies, vocational colleges and private colleges were eliminated, 42 public universities or colleges with independent legal qualification were selected for their providing undergraduate academic program of IMIS oriented toward health and medicine, and keeping recruiting candidates from 2013 to 2016 Other public universities or colleges which did not undertake this program were excluded. At last, 11 TCM colleges and 31 medical colleges were determined as shown in the following TABLE I.
Sponsored by the research program Study on the Quality Guarantee and Evaluation Indicator System for Graduation Theses of Undergraduates Majoring in Informatics in Medical Colleges (No:2012B089), which had originated from Hubei Education Science 12th Five-Year Plan. 
TABLE I. COLLEGES OFFERING UNDERGRADUATE ACADEMIC PROGRAM OF IMIS ORIENTED TOWARD HEALTH AND MEDICINE FROM 2013 TO 2016

\begin{tabular}{|c|c|c|}
\hline Type & Number & List of Colleges \\
\hline TCM Colleges & 11 & Beijing/Nanjing/Liaoning/Henan/Guangxi/Fujian/Anhui/Shandong/Hubei/Hunan/Shanxi University of TCM \\
\hline Medical Colleges & $31^{\mathrm{a}}$ & $\begin{array}{l}\text { Guangdong Pharmaceutical University, Anhui Medical University, Hubei University of Medicine, Hainan } \\
\text { Medical University, Guilin Medical University, Guangzhou Medical University, Guangdong Medical } \\
\text { University, North Sichuan Medical College, Chengdu Medical College, Changzhi Medical College, Bin zhou } \\
\text { Medical University, Bengbu Medical College, Guang xi Medical University, China Medical University, China } \\
\text { Pharmaceutical University, Xin xiang Medical University, Xinjiang Medical University, Wannan Medical } \\
\text { College Wenzhou Medical University, Southwest Medical University, Taishan Medical University, Shanxi } \\
\text { Medical University, ChongQing Medical University, Qiqihar Medical University, Inner Mongolia Medical } \\
\text { University, Mudanjiang Medical University, Jining Medical University, Jilin Medical University, Tongji } \\
\text { Medical College of Huazhong University of Science and Technology, School of Public Health Jilin } \\
\text { University, Baotou Medical College }\end{array}$ \\
\hline
\end{tabular}

a. The specialty of Bioinformatics in Harbin Medical University, and the specialty of Medical In formatics in Central South University and Nantong University are not included. The specialty of IMIS and the specialty of The specialty of Bioinformatics in Harbin Medical University, and the specialty of Medical In formatics in Central
IMIS oriented toward health and medicine in Shanxi University of TCM were not differentiated and both included.

\section{B. Sources of Professional Enrollment Materials}

The above 42 colleges' official websites and the websites of CHSI, EOL offered a large number of enrollment materials of various specialties. Additionally, the number of graduates, recruits and undergraduates of 11 TCM colleges from 2013 to 2015 were achieved from Yearbook of Traditional Chinese Medicine of China (Administration Volume)[6].

\section{Methods of Data Collecting and Processing}

The 42 colleges' IMIS enrollment materials were manually collected from the above sources by juniors and seniors, who were majoring in IMIS in Hubei University of TCM. If the IMIS enrollment materials gotten from the websites of CHSI and EOL, were not complete or conflicted with the corresponding data publicized on these colleges' official websites, the latters were confirmed and adopted. The data about graduates, recruits and undergraduates of 11 TCM colleges were inputted and checked by two juniors. All research materials were cleaned in Excel 2010 before they were stored into Access 2010 and finally analyzed by SPSS 19.0.

\section{RESULTS}

\section{A. The Amount of Enrollment Scale}

As described in the following TABLE II and III, from 2013 to 2016 the accumulative IMIS planning enrollment volume of 11 TCM colleges was 2219, which occupied about $22.17 \%$ of the total for the same period. Different from medical colleges keeping steady and decreasing a little, the accumulative IMIS planning enrollment volume in 11 TCM colleges remained bigger than 600, and in 2016, it increased by about $16.61 \%$ than 2013 , although it decreased from the climax in 2014. At the same time, it took over more than a quarter of the total of 42 colleges, and the corresponding proportion rose from $22.26 \%$ to $27.02 \%$. Overall, the total IMIS planning enrollment volume in 42 colleges was decreased slowly year by year. The average scale in TCM colleges was also gradually drawn back, and at present, it was a little lower than medical colleges after a sharp expansion.

TABLE II. THE COUNT OF COLLEGESOFFERING IMIS ORIENTED TOWARD HEALTH AND MEDICINE AND PLANNING ENROLLMENT VOLUME FROM 2013 TO 2016

\begin{tabular}{ccccc}
\hline College Type & $\mathbf{2 0 1 3}$ & $\mathbf{2 0 1 4}$ & $\mathbf{2 0 1 5}$ & $\mathbf{2 0 1 6}$ \\
\hline TCM Colleges & $602(7)$ & $828(9)$ & $787(11)$ & $702(11)$ \\
Medical Colleges & $2102(27)$ & $2021(29)$ & $1804(28)$ & $1896(31)$ \\
\hline Total & $2704(34)$ & $2849(38)$ & $2591(39)$ & $2598(42)$ \\
\hline
\end{tabular}

TABLE III. THE ENROLLMENT SCALE OF IMIS FROM 2013 TO 2016

\begin{tabular}{cccccc}
\hline Type & $\mathbf{2 0 1 3}$ & $\mathbf{2 0 1 4}$ & $\mathbf{2 0 1 5}$ & $\mathbf{2 0 1 6}$ & All \\
\hline TCM & 92 & 200 & 100 & 60 & 90 \\
Colleges & $(60,200)^{\mathrm{a}}$ & $(60,260)$ & $(60,200)$ & $(50,90)$ & $(60,200)$ \\
Medical & 100 & 100 & 80 & 68 & 84 \\
Colleges & $(55,155)$ & $(50,120)$ & $(50,111)$ & $(50,100)$ & $(50,120)$ \\
\hline \multirow{2}{*}{ Total } & 100 & 100 & 84 & 60 & 88 \\
& $(60,200)$ & $(58,151)$ & $(50,117)$ & $(50,100)$ & $(53,120)$ \\
\hline & & & a. $92(60,200)$ Means $\mathrm{P}_{50}\left(\mathrm{P}_{25}, \mathrm{P}_{75}\right)$
\end{tabular}

\section{B. Province Distribution of IMIS Enrollment plan}

From the following TABLE IV , $71.02 \%$ of the accumulative IMIS planning enrollment volume of 11 TCM colleges were distributed in six provinces, including Shandong, Anhui, Jiangsu, Shanxi, Hubei, and especially Henan, which nearly took possession of one quarter, but none of that was dispensed to Shanghai and Xizang. 12 provinces or municipalities had less than $1 \%$ of their planning enrollment volumes originated from 11 TCM colleges from 2013 to 2016 . By contrast, 31 medical colleges dispensed their IMIS enrollment plans into every province, and $72.10 \%$ were concentrated in eight provinces, including Guangdong, Anhui, Shandong, Shanxi, Sichuan, Inner Mongolia, Henan. The most proportion, about $16.44 \%$, was hold by Guangdong province. And also 12 provinces or municipalities had been allocated less than $1 \%$ of their planning enrollment volume from 31 medical colleges from 2013 to 2016, and six of them were the same as that of TCM colleges, consisting of Beijing, Tianjin, Ningxia, Qinghai, Shanxi and Xinjiang. When the enrollment source in each province was considered, only five provinces had more than $50 \%$ of their planning enrollment volume gathered from TCM colleges, including Fujian, Henan, Hunan, Jiangsu, Hubei. For the other six provinces or municipalities like Inner Mongolia, Xinjiang, Sichuan, Guangdong, Shanghai, Xizang, the proportion of their planning enrollment volume were all less than $10 \%$ originated from TCM colleges. 
TABLE IV. THE ACCUMULATIVE IMIS PLANNINGENROLLMENT VOLUME AND CORRESPONDING CONSTITUENT RATIO FOR EACH PROVINCE

\begin{tabular}{|c|c|c|c|}
\hline Provinces & All Colleges & TCM Colleges & Medical Colleges \\
\hline Guangdong & 1303(12.13) & $17(0.58)$ & $1286(16.44)$ \\
\hline Anhui & $1294(12.05)$ & $275(9.42)$ & 1019(13.03) \\
\hline Shandong & $1214(11.30)$ & 399(13.67) & $815(10.42)$ \\
\hline Henan & 1009(9.39) & 694(23.78) & $315(4.03)$ \\
\hline Shanxi & 993(9.24) & 252(8.63) & 741(9.47) \\
\hline Guangxi & $735(6.84)$ & 109(3.73) & $626(8.00)$ \\
\hline Sichuan & $504(4.69)$ & $28(0.96)$ & $476(6.08)$ \\
\hline Jiangsu & $465(4.33)$ & 273(9.35) & $192(2.45)$ \\
\hline Inner Mongolia & 391(3.64) & $29(0.99)$ & $362(4.63)$ \\
\hline Hubei & 358(3.33) & $180(6.17)$ & $178(2.28)$ \\
\hline Zhejiang & $294(2.74)$ & $36(1.23)$ & 258(3.30) \\
\hline Heilongjiang & $259(2.41)$ & $33(1.13)$ & $226(2.89)$ \\
\hline Jilin & 199(1.85) & $34(1.16)$ & $165(2.11)$ \\
\hline Hunan & 198(1.84) & $132(4.52)$ & $66(0.84)$ \\
\hline Chongqing & 192(1.79) & $27(0.92)$ & $165(2.11)$ \\
\hline Fujian & 158(1.47) & 115(3.94) & $43(0.55)$ \\
\hline Guizhou & $157(1.46)$ & $44(1.51)$ & $113(1.44)$ \\
\hline Liaoning & $135(1.26)$ & $20(0.69)$ & $115(1.47)$ \\
\hline Gansu & $130(1.21)$ & $34(1.16)$ & $96(1.23)$ \\
\hline Hainan & $130(1.21)$ & $23(0.79)$ & 107(1.37) \\
\hline Yunnan & 117(1.09) & $30(1.03)$ & 87(1.11) \\
\hline Hebei & $100(0.93)$ & $33(1.13)$ & $67(0.86)$ \\
\hline Jiangxi & $83(0.77)$ & $32(1.10)$ & $51(0.65)$ \\
\hline Xinjiang & $81(0.75)$ & $5(0.17)$ & $76(0.97)$ \\
\hline Shanxi & $76(0.71)$ & $22(0.75)$ & $54(0.69)$ \\
\hline Ningxia & $48(0.45)$ & $15(0.51)$ & $33(0.42)$ \\
\hline Tianjin & $47(0.44)$ & $16(0.55)$ & $31(0.40)$ \\
\hline Qinghai & $39(0.36)$ & $9(0.31)$ & $30(0.38)$ \\
\hline Beijing & $23(0.21)$ & $3(0.10)$ & $20(0.26)$ \\
\hline Shanghai & $9(0.08)$ & $0(0.00)$ & $9(0.12)$ \\
\hline Xizang & $1(0.01)$ & $0(0.00)$ & $1(0.01)$ \\
\hline Total & 10742 & 2919 & 7823 \\
\hline
\end{tabular}

a. $\chi 2=2409.96, P<0.001$

\section{Region Distribution of IMIS Enrollment plan}

As shown in TABLE $V$, from the view of region distribution, the total IMIS planning enrollment volume of 42 colleges was mainly allocated in middle region, which was followed by east region and west region. A distinct imbalance existed in the region distribution of IMIS enrollment plans of 11 TCM colleges, since $55.91 \%$ was in middle region and only $12.06 \%$ in west region. It seemed to be more balanced for the region distribution of IMIS enrollment plans of 31 Medical colleges. Overall, IMIS enrollment plans in all regions mainly sourced from medical colleges, while that from TCM colleges just took up about $24.11 \%$ in east region, $37.15 \%$ in middle region and $14.25 \%$ in west region from 2013 to 2016.

TABLE V. REGION DIST RIBUTION OF IMIS ENROLLMENT PLAN

\begin{tabular}{crrr}
\hline Region & \multicolumn{1}{c}{ All Colleges } & TCM Colleges & \multicolumn{1}{c}{ Medical Colleges } \\
\hline East Region $^{\mathrm{a}}$ & $3878(36.10)$ & $935(32.03)$ & $2943(37.62)$ \\
Middle Region & $4393(40.90)$ & $1632(55.91)$ & $2761(35.29)$ \\
West Region & $2471(23.00)$ & $352(12.06)$ & $2119(27.09)$ \\
\hline Total & 10742 & 2919 & 7823 \\
\hline
\end{tabular}

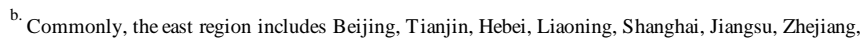
Fujian, Shandong, Guangdong, Hainan. The middle region includes Shanxi, Jilin, Heilongjiang, Anhui, Jiangxi, Henan, Hubei, Hunan. The west region includes
Hel Chongqing, Sichuan, Guizhou, Yunnan, Xizang, Shanxi, Gansu, Qinghai, Ningxia,
Xinjiang, Guangxi, and Inner Mongolia.

c. $\chi 2=448.03, \mathrm{P}<0.001$.

From TABLE VI, the proportion of IMIS planning enrollment volume originated from 11 TCM colleges in middle region was less and less, while in east region and west region the proportions both increased gradually. This change brought about that the source of IMIS enrollment plans in east region and west region gotten from 11 TCM colleges, rose up to $26.92 \%$ and $16.87 \%$ separately.

TABLE VI. REGION DISTRIBUTION EVOLUTION OF IMIS ENROLLMENT PLANS OF TCM COLLEGES FROM 2013 TO 2016

\begin{tabular}{crrrr}
\hline Region & $\mathbf{2 0 1 3}$ & $\mathbf{2 0 1 4}$ & $\mathbf{2 0 1 5}$ & $\mathbf{2 0 1 6}$ \\
\hline East Region $^{\mathrm{a}}$ & $164(27.24)$ & $210(25.36)$ & $301(38.25)$ & $260(37.04)$ \\
Middle Region & $403(66.94)$ & $548(66.18)$ & $352(44.73)$ & $329(46.87)$ \\
West Region & $35(5.81)$ & $70(8.45)$ & $134(17.03)$ & $113(16.10)$ \\
\hline Total & 602 & 828 & 787 & 702 \\
\hline \multicolumn{2}{c}{${ }^{\text {a. }}$ The method of region divide is the same as the above Table V. } \\
\multicolumn{4}{r}{${ }^{2}=141.39, \mathrm{P}<0.001}$.
\end{tabular}

\section{District Distribution of IMIS Enrollment plan}

As described in the following TABLE VII, nearly $80 \%$ of the accumulative IMIS planning enrollment volume of 11 TCM colleges, were assigned to middle-of-south and eastern China, and about $10 \%$ were apportioned to southwest, northeast and northwest. It was similar to the distribution feature of the total IMIS planning enrollment volume of 42 colleges, but embraced more imbalances.

In all districts, lower than $1 / 3$ of the accumulative IMIS planning enrollment volume were originated from 11 TCM colleges. However, with the exception of northeast, the other districts' proportions were increased more or less from 2013 to 2016. The proportion of eastern China rose year by year and came up to $37.58 \%$ in 2016.

TABLE VII. DISTRICT DIST RIBUTION OF IMIS ENROLLMENT PLAN

\begin{tabular}{cccc}
\hline District & All Colleges & TCM Colleges & Medical Colleges \\
\hline Northeast $^{\mathrm{a}}$ & $593(5.52)$ & $87(2.98)$ & $506(6.47)$ \\
Northern China & $1554(14.47)$ & $333(11.41)$ & $1221(15.61)$ \\
Eastern China & $3517(32.74)$ & $1130(38.71)$ & $2387(30.51)$ \\
Northwest & $374(3.48)$ & $85(2.91)$ & $289(3.69)$ \\
Southwest & $971(9.04)$ & $129(4.42)$ & $842(10.76)$ \\
Southern China & $3733(34.75)$ & $1155(39.57)$ & $2578(32.95)$ \\
\hline Total & 10742 & 2919 & 7823 \\
\hline c. Commonly, the Northern China distinct includes Beijing, Tianjin, Hebei, Shanxi and Inner Mongolia. \\
\\
& The Northeast China distinct includes Liaoning, Jilin and Heilongjiang. The Eastern \\
& China distinct includes Shanghai, Jiangsu, Zhejiang, Anhui, Fujian, Jiangxi and \\
& Shandong. The Southern China distinct includes Henan, Hubei, Hunan, Guangdong, \\
& Guangxi and Hainan. The Southwest China distinct includes Chongqing, \\
& Sichuan,, Guizhou, Yunnan and Xizang. The Northwest China distinct includes Shanxi, \\
& & Gansu, Qinghai, Ningxia and Xinjiang. \\
& & & d. $2=241.55, P<0.001$.
\end{tabular}

\section{E. Discipline Distribution of IMIS Enrollment plan}

The majority of 42 colleges recruited science candidates in their IMIS enrollment plans, only $9.05 \%$ of which were taken out to accept liberal arts candidates. In 11 TCM colleges, there were about $2.91 \%$ of the accumulation of IMIS enrollment plans oriented toward liberal arts candidates, and the proportion was much lower than that of 31 medical colleges. The proportion of liberal arts candidates decreased from $10.91 \%$ in 2013 to $8.01 \%$ in 2016 year by year $(\chi 2=80.39, P<0.001)$. In 2016, all TCM colleges only recruited science candidates, while two medical colleges remained recruiting liberal arts candidates and another four medical colleges recruited both of liberal arts candidates and science candidates. 


\section{F. Comparison of IMIS Enrollment plan and Actual enrollment}

The actual enrollment volume describes that how many candidates have finished registering procedure officially in a college each year. The ratio of IMIS planning enrollment to actual enrollment had risen up from 1:0.86 in 2013 to 1:1.04 in 2015, which indicated that in recent years the implementation of IMIS enrollment plans of TCM colleges tended to be better. At the same time, for most of TCM colleges, there still existed enrollment gaps to some extent between IMIS planning enrollment and actual enrollment. Especially, colleges like Fujian university of TCM and Guangxi university of TCM had even interrupted their IMIS enrollment plan in 2013, which prompted that the implementation of IMIS enrollment plan was still confronted with challenges and not stable.

\section{Discussion}

\section{A. Analysis of the features of IMIS enrollment plan}

- The total planning enrollment volume fluctuates significantly. The total planned enrollment of IMIS in TCM Colleges shows a sharp expansion and then gradually retracts, and obviously different from medical colleges which keeps a steady and slightly decrease.

- The average enrollment scale is larger. The average planned enrollment scale of IMIS in TCM Colleges is higher than the average level of all colleges in the same period and higher than Medical colleges (slightly lower than that of medical colleges in 2016).

- The regional distribution is significant different. Enrollment sources of IMIS in TCM colleges are mainly distributed in a few central provinces including Henan, Shandong, Anhui, Jiangsu, Shanxi, Hubei etc. But in the east economically developed areas, the northeast and the west, especially in the relatively backward areas such as the southwest and the northwest, minority areas are less distributed. Compared with the medical colleges the degree of imbalance between provinces, regions and areas is even more serious.

- The structure and quality of enrollment sources are improving year by year. The structure of enrollment sources of IMIS in TCM Colleges has changed from the second tier universities which accept both arts and sciences students to the pattern that the proportion of first tier universities increases year by year and only the students of science are accepted, and the actual enrollment gap has gradually narrowed.

In summary, the enrollment plan of IMIS in TCM Colleges is in the transition stage of extensive development characterized by scale expansion to intensive development characterized by source structure and quality optimization.

\section{B. Major problems of IMIS enrollment plan}

The personnel training of IMIS in TCM Colleges is mainly oriented to the health and TCM industries, and the fundamental goal is to train compound talents who meet the needs of informationization of TCM and ethnomedicine. However, in recent years, the characteristics of the enrollment sources of
IMIS in TCM colleges are not consistent with the requirements of their professional orientation and training objectives.

- The enrollment scale and policy are instability. The enrollment scale of IMIS in Henan University of Chinese Medicine and Shanxi University of Chinese Medicine has drastically concussion, even in Guangxi University of Chinese Medicine suspended enrollment in 2013. The unsustainability of enrollment scale and policy can easily affect the expectation of college entrance voluntary.

- The enrollment gap generally exists. Low social recognition of IMIS in TCM colleges leads to enrollment gap and low first aspiration acceptance. This phenomenon has persisted for many years and has not been reversed.

- It is not consistent with the needs of informationization of TCM and ethnomedicine. The quotas are too few in the strong provinces and big provinces such as Guangdong, Sichuan, Shanxi, Liaoning etc. and the same in the relatively backward areas such as the southwest, the northwest and minority areas.

- The distribution of enrollment sources is overlapped or misplaced with medical colleges. Too many quotas were put into these areas which are also the key enrollment areas of medical colleges, On the other hand, relatively fewer quotas were put into those areas which are the least enrollment areas of medical colleges. This aggravates the competition for high-quality students in some areas, leading to the waste of some quotas.

- The contradiction between scale expansion and optimization of the quality of enrollment sources is very prominent. The enrollment scale is higher than medical colleges and the overall enrollment rate in first tier universities is still low. Under the condition of limited teaching resources, the contradiction between expanding enrollment scale and optimizing the quality of students will become more prominent.

\section{CONCLUSION}

Anyone can not deny that making and implementing more reasonable and practicable enrollment plan is crucial to raise IMIS cultivation quality for TCM colleges. TCM colleges undertaking IMIS talents cultivation should make best use of opportunities, such as the reform of college recruitment system, healthcare Bigdata developed with high speed and TCM being revitalized to optimizing their IMIS enrollment plan. From what was discussed above, at least suggestions of four aspects could be considered as follows.

- The scale of IMIS enrollment plan should be more stable. TCM colleges should concentrate on realizing its connotative development, and it is advisable for them to keep the scale of IMIS enrollment plan steady or shrinking appropriately. More attention should be paid on profession brand building and how to protrude its characteristics of TCM informatics. 
- The distribution and structure of IMIS enrollment plan awaits to be improved. In order to meet the talent requirements of TCM informatization construction, it may be more suitable for TCM colleges to enlarge the IMIS enrollment plan in some provinces which developed better in TCM like Guangdong and Sichuan province, and temperately increased the proportion of IMIS enrollment plan in east area and west area. Also, it is important to expand the source of IMIS enrollment plan in minority areas to support the informatizaion construction of ethnomedicine. At the same time, the distribution of TCM colleges should be adjusted to be complementary with the medical colleges.

- Expand the channels of IMIS enrollment plan. Some sources of IMIS enrollment plan, such as National Special Enrollment plan, Special Enrollment plan for Cooperative among local authorities, Rural Special Enrollment plan and etc., could be taken into account and enlarged moderately. Orientation training or Joint training of IMIS enrollment plan could be formulated through strengthening the cooperation between TCM colleges and all kinds of hospitals or medical treatment groups.

- TCM colleges should attach more importance on publicity. Students are the best publicity channel for any specialty. Nowadays, a large amount of undergraduates in TCM colleges took part in various contests, such as Internet plus Competition, Programming Competition, Innovation and Entrepreneurship Competition, Mathematical Modeling Competition and so on, which attracted widespread social attention and offered them with great professional experiences and success. Their achievements could be publicized widely to foster selfconfidence and satisfaction among the students majoring in IMIS in TCM colleges. Meanwhile, social media like Wechat and Microblog, websites and advertisements, could be synthetically utilized to propagate the talent value and magnificent prospect of
IMIS, prominent scientific research results and teaching achievements, classic hospital informatization cases and the stories of meritocracy in the field of TCM informatization. All of these countermeasures will have the benefit of rectifying the society cognition for the cultivation of IMIS in TCM colleges.

\section{ACKNOWLEDGEMENT}

This research was financially supported by Hubei Provincial Department of Education. Thanks Dr. SUN for her great help in paper revising and also undergraduates who participated in this study for their hard work in data collecting and processing.

\section{REFERENCES}

[1] Weiwei YU, Jihong LI, Liangbo DING, "Analysis on the current situation of profession education of Medical Informatics," Health Vocational Education. Lanzhou, vol. 35, pp. 5-7, December 2017. (In Chinese)

[2] Tingting LIU, Changyi LI, Litao ZHANG, Study on the cultivation mode of the specialty of IMIS in Bigdata times," China Electric Power Education. Beijing, pp. 48-50. February 2014. (In Chinese)

[3] Yanqiu SUN, Yan YAN, Tianyu WANG, "Research on Teaching Reform of Information Management and Information System Specialty of Chinese Traditional Medicine Colleges and Universities,” Journal of Liaoning University of Traditional Chinese Medicine. Shenyang, vol. 17, pp. 141-143. April 2015. (In Chinese)

[4] Haifeng YANG, Zhen ZHAO, Yangbo SUN, “Analysis on Practical Teaching System of Information Management and System Specialty in TCM Colleges and Universities,” Journal of Hubei University of Chinese Medicine. Wuhan, vol. 18, pp. 117-121. April 2016. (In Chinese)

[5] Xue ZHANG, Jinfang ZHANG, "Investigation and analysis on the enrollment scale of non-medical specialt ies in Chinese TCM colleges in 2013,” China Market. Beijing, pp. 64-65. December 2014. (In Chinese)

[6] SATCM. Chinese Medicine Yearbook. China Press of Traditional Chinese Medicine, Beijing 2013, 2014, 2015, 2016. (In Chinese) 